\title{
La revista Aisthesis y la poesía
}

\author{
Jaime Blume Sánchez \\ Instituto de Estética, Facultad de Filosofía, Pontificia Universidad Católica de Chile. \\ jblume@uc.cl
}

El mundo de la poesía se abre aquí hacia los infinitos campos que la incluyen. El primero de ellos es el que dice relación con su esencia. En este aspecto, la mirada del maestro Kupareo es insoslayable. Desde un punto inicialmente tomista, pero enriquecido con aportes renovados de la disciplina estética, Kupareo propone algo que dentro de su sistema es fundamental. Como toda creación humana, la poesía está circunscrita a un tiempo y un espacio determinados. En cuanto tal, su materialidad es absolutamente contingente e individual y su realidad se limita al variable número de versos que le dan vida. Pese a ello, su misma condición singular amplía su significado, convirtiendo lo concreto en algo universal. Dicho en breve, se trata de la facultad que tiene lo concreto individual artístico de sugerir una abstracción universal. Hablando, por ejemplo, de un día de veinticuatro horas, nuestra mente se abre a la comprensión de esa dimensión abarcadora que se llama "tiempo". En esta nueva dimensión, el tiempo puede experimentarse como infinito o, por el contrario, desvanecerse en segundos. Esta es una de las características esenciales del arte poético. Otra es la que desarrolla Radoslav Ivelic en distintos artículos. Se trata de la capacidad de transfigurar la realidad, de modo tal que si digo "me duele septiembre", no me estoy refiriendo a un ataque de alergia primaveral, sino a la desazón que pudo provocar en mí el golpe militar, ocurrido justamente en septiembre de 1973.

Los arriba señaladas son atributos que apuntan a determinar la esencia de la poesía. Pero tan luego como se despeja el tema de la esencia poética surgen otros igualmente apremiantes. Está, por ejemplo, el de la vinculación de la poesía con la verdad. Cuando se habla de "verdad", ¿se trata solamente de lo que atestiguan nuestros sentidos o es posible hablar de un cierto intuitivo asedio lírico a una determinada realidad, que va mucho más lejos y más hondo que un simple registro sensorial? Jorge 
Montoya se detiene con particular agudeza en semejante problema. Pero así como la poesía incursiona en el campo de la verdad, también dicho proceso se realiza en el ámbito del bien. En dicho espacio no solo la razón está comprometida, sino también la voluntad. Es el eterno problema de la "censura", que experimenta real inquietud no solo cuando la poesía se aventura libremente en el ámbito de la sexualidad, sino que también frunce el ceño cuando el escrito emite juicios "osados" frente a valores considerados inamovibles. Ahondando en el tema, y siempre en el campo teórico, resulta legítimo analizar la relación entre la poesía y la moral. El tema no es liviano. Hubo épocas en que algunos poetas fueron tildados de "malditos", no solo por lo rupturista de sus formas poéticas o por las situaciones éticas a las que aludían, sino que también por sus conductas u opciones sexuales. Osvaldo Lira, con la profundidad que lo caracteriza, analiza un tema tan vidrioso como el señalado.

Vinculado con lo dicho más arriba, la poesía tiende sus redes al ámbito de la religión. Y esto casi por natural deriva. Es lo que un poeta panameño, José Guillermo Ros-Zanet, señala con intuición profunda: "Creo que las palabras escritas son signos de las palabras habladas, que las palabras habladas y escritas son signos del pensamiento y que el pensamiento es como el signo del hombre, que el hombre es signo del ser. Y el ser es como el signo de Dios. Y Dios es su propio signo. El Signo Absoluto. El Verbo y el Verbo Encarnado".

Siempre en la línea de profundizar en el misterio de la vinculación de lo religioso con la poesía, el aporte del profesor Ernesto Livacic y su equipo resulta necesario. Ello ocurre cuando se analiza la obra poética de autores determinados y se procura descubrir en ella los vestigios de una posible huella de fe o de una oscura aspiración a lo absoluto. Lo señalado no agota obviamente el tema. Es justamente en este punto donde Osvaldo Lira ataca derechamente la conexión que puede existir entre la poesía y la mística, afirmando que en un caso determinado, en la obra de Juan Ramón Jiménez, es legítimo hablar de una mística natural, algo así como el acceso a un absoluto, sin Dios en primera instancia, pero de algún modo exigiendo dar el paso decisivo que permite aproximarse a la divinidad. Pero la poesía no solo se desenvuelve en el espacio de las grandes aspiraciones. Lo concreto vital, propio de la vida de todos los días, también le compete. Según lo ya visto en párrafos anteriores, la poesía tiene una especie de particular tropismo que la lleva a vincularse con otras artes afines. Es el caso de la pintura, que en su dimensión expresionista abstracta establece un enriquecedor diálogo con la poesía. Alberto Santa María analiza el tema con atinada agudeza. Es también el caso de la educación, que ofrece a la poesía generoso campo de interlocución. Souriau, Radoslav Ivelic y Luis Hernán Errázuriz estudian con particular empeño un tema tan importante como el señalado.

En esta especie de visión sintética del misterio de la poesía, conviene rescatar otras aristas susceptibles de ser analizadas. Es el caso, por ejemplo, de su fluidez histórica y social, que le permite manifestarse en distintas épocas y en distintos medios. Una rápida revisión de los volúmenes que componen la colección de la revista Aisthesis 
nos entrega la presencia de estudios sobre la historia de la poesía chilena. En concreto, Hugo Montes establece una pedagógica presentación de generaciones y autores pertenecientes a la poesía chilena de hoy, mientras Carolina Merino procura estudiar la suerte de los poetas que permanecieron en Chile luego del golpe militar, sus puntos de encuentro y disidencias, comparando esa realidad con la suerte de los que tuvieron que salir al exilio. Ya en el campo de la poesía étnica, Gilda Luongo plantea el caso de las poetas mapuche, tanto en su dimensión íntima como en su vinculación social, al paso que Mariana Bonano apunta a las estéticas coloniales y apropiaciones de la cultura popular que ocurren en la zona de la poesía americana.

Como hemos visto, la revista Aisthesis, a través de los escritos de destacados autores, tanto nacionales como extranjeros, ha estudiado temas de gran relevancia dentro del campo que le es propio. Los primeros en términos de amplitud de visión corresponden al arte, la verdad y la belleza, y a la dimensión del bien y el mal al interior de una obra. A dichas consideraciones sigue el capítulo de las causas del fenómeno artístico, que menciona a las musas inspiradoras, al genio del poeta, a la imaginación, los sueños, la locura, los instintos reprimidos y el inconsciente colectivo. En lo que a la materialización concreta de la obra de arte se refiere, el tema de la mímesis y de la creación de una nueva realidad recibe particular consideración. Una vez surgida la obra de arte e instalada en el horizonte de la existencia material, de inmediato se presentan los problemas de su vinculación con la moral y la religión, aspectos de los que Aisthesis también se hace cargo.

Ya en el campo específico de la poesía, lo que interesa en primer término es averiguar cuál podría ser su esencia. En esa línea se postulan dos posibilidades, distintas entre sí, pero complementarias. Una se refiere a la capacidad de lo poético de proyectar su individualidad concreta a una universalidad abstracta, mientras la segunda privilegia la aptitud de transfigurar la realidad. Consistente con consideraciones teóricas propias de la teoría del arte, la poesía también incorpora a su esencia los temas de la verdad y el bien, lo que trae como consecuencia la vinculación de la materia lírica con la moral y la religión, y más específicamente, con la fe. En ese campo, merecen particular consideración tanto la ortodoxia de una confesión militante como la búsqueda a oscuras de un encuentro con lo absoluto.

Pero la poesía no es una especie de entelequia desarraigada de la realidad. Antes al contrario, no pocas veces su aparición es expresión de la intimidad del poeta o la respuesta a una situación exterior concreta. De ahí la vinculación que la poesía tiene con el momento histórico al que aparece. Lo dicho da pie a una historia de la poesía o a su dependencia de un factor determinado de la historia nacional. Ello explica estudios como los que se refieren a la poesía femenina, étnica o popular. En síntesis, y a lo largo de su medio siglo de existencia, la revista Aisthesis se ha abocado al estudio de un dilatado horizonte temático, que incluye teorías estéticas, crítica poética, estudio de poetas individuales y de expresiones colectivas generacionales, así como su vinculación con áreas que, sin ser estrictamente poéticas, interesan a sus intenciones. 